Original Article

\title{
Effectiveness of Child To Child Approach on Practice of Hand Washing Among School Children in a Selected School at Mangalore
}

\section{Smitha Mariam Mathew ${ }^{1}$, Sujatha $\mathbf{R}^{2}$}

${ }^{1} \mathrm{M} \mathrm{Sc}(\mathrm{N})$ Student, ${ }^{2}$ Prof. \& HOD, Department of Child Health Nursing, Nitte Usha Institute Of Nursing Sciences, Constituent College of Nitte University, Kotekar Beeri Road, Paneer, Deralakatte, M angalore- 575 018, Karnataka, India

Corresponding author : Sujatha R., Prof. \& HOD, Department of Child Health Nursing, Nitte Usha Institute of Nursing Sciences, Constituent College of Nitte University, Kotekar Beeri Road, Paneer, Deralakatte, M angalore- 575 018, Karnataka, India.

E-mail : sujathakannappan@gmail.com

Received : : 19.09.2016

Review Completed : 03.05.2017

Accepted : : 01.01.2018

Keywords : Child to child approach, Hand washing.

\begin{tabular}{|c|}
\hline Access this article online \\
\hline Quick Response Code \\
\hline
\end{tabular}

Abstract

Objective: Effectiveness of child to child approach on practice of hand washing.

Design: Quantitative evaluative research approach \& pre experimental - One group pre-test post-test design was used.

Setting: This study was conducted in a selected rural school (Aided higher primary school, Pavoor-Harekala) at M angalore.

Participants: The populations covered were school children in the age group 9-10 years who met the inclusion criteria and studying in a rural school at Mangalore. 75 students from Aided higher primary school within the age $9-10$ years and studying in 4 th to 5 th class were selected by using purposive sampling.

Main outcome measures: M ain outcome measure was whether the school children are able to practice the hand washing technique. Data collection was collected by using Demographic proforma and Checklist (to assess the practice of hand washing).

Results: Data was analyzed using descriptive and inferential statistics. The mean post-test score on hand washing of group 1 (12.46) and group 2 (12.05) was higher as compared with pre-test score of group I (12.46) and group II (12.05) and the " $p$ " value is $\varangle .05$. So the child to child approach was effective to teach the children hand washing technique. There was no association between the selected demographic variables and pre-test hand washing scores

Conclusions: This study concludes that through proper training and motivation by peer group, that is child to child approach was an effective method to teach the children healthy habits like hand washing and other common issues concerning children.

\section{Introduction}

Hand washing is one of the most important component in infection control activities. Good hand washing is the primary barrier to many health problems like food poisoning, gastroenteritis, worm infestations, diarrheal diseases, cold, flu, pneumonia, scabies infection and trachoma. There is undisputed evidence that strict adherence to hand washing reduces the risk of crosstransmission of infections. School is the second home for children where they spend one-fourth of their life and learn a lot of things which lays the foundation for building their character.
School children are easily approachable and teachable as they achieve a sense of self- confidence by learning, competing, performing successfully and receiving recognition from others. They can act as important change agents in the society. Child to child approach encourage children to take initiative to learn and teach others thereby giving them a satisfaction and pleasure in interacting with others and feel pride in achievement. Here the learning becomes a fun activity and they can act as important change agents in the society. Hence the study was conceived to determine the effectiveness of child to child approach on hand washing among school children. The aim 
of this study was to evaluate the effect of child to child approach on hand washing practices.

\section{Hypothesis}

$\mathrm{H} 1$ : The mean post-test practice scores of school children regarding hand washing will be significantly higher than their mean pre-test practice scores.
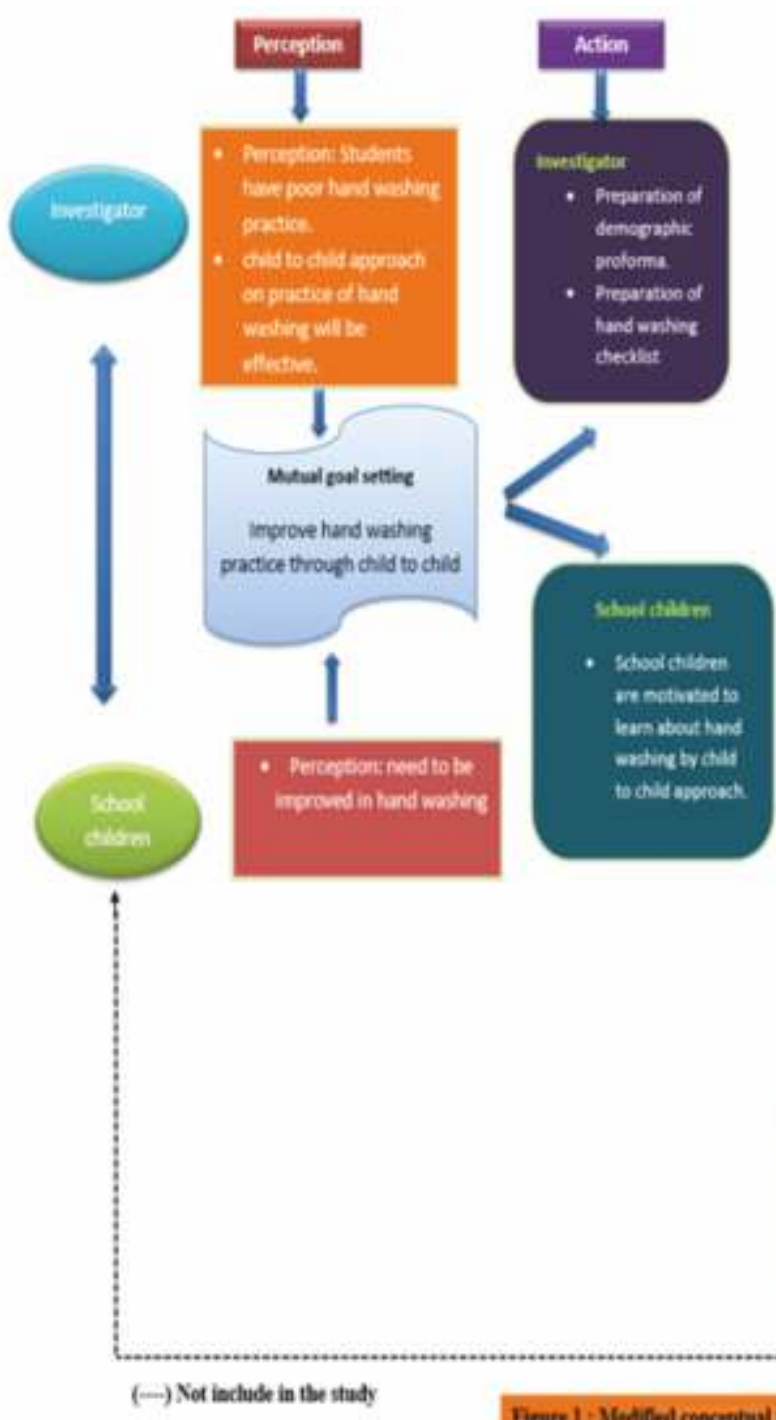

Conceptual Frame Work : Imogene king's goal attainment model (1981) was modified by the investigator to form the conceptual framework. This model focuses on interpersonal relationship between the client and the mainly four phases: perception, action, interaction and transaction.

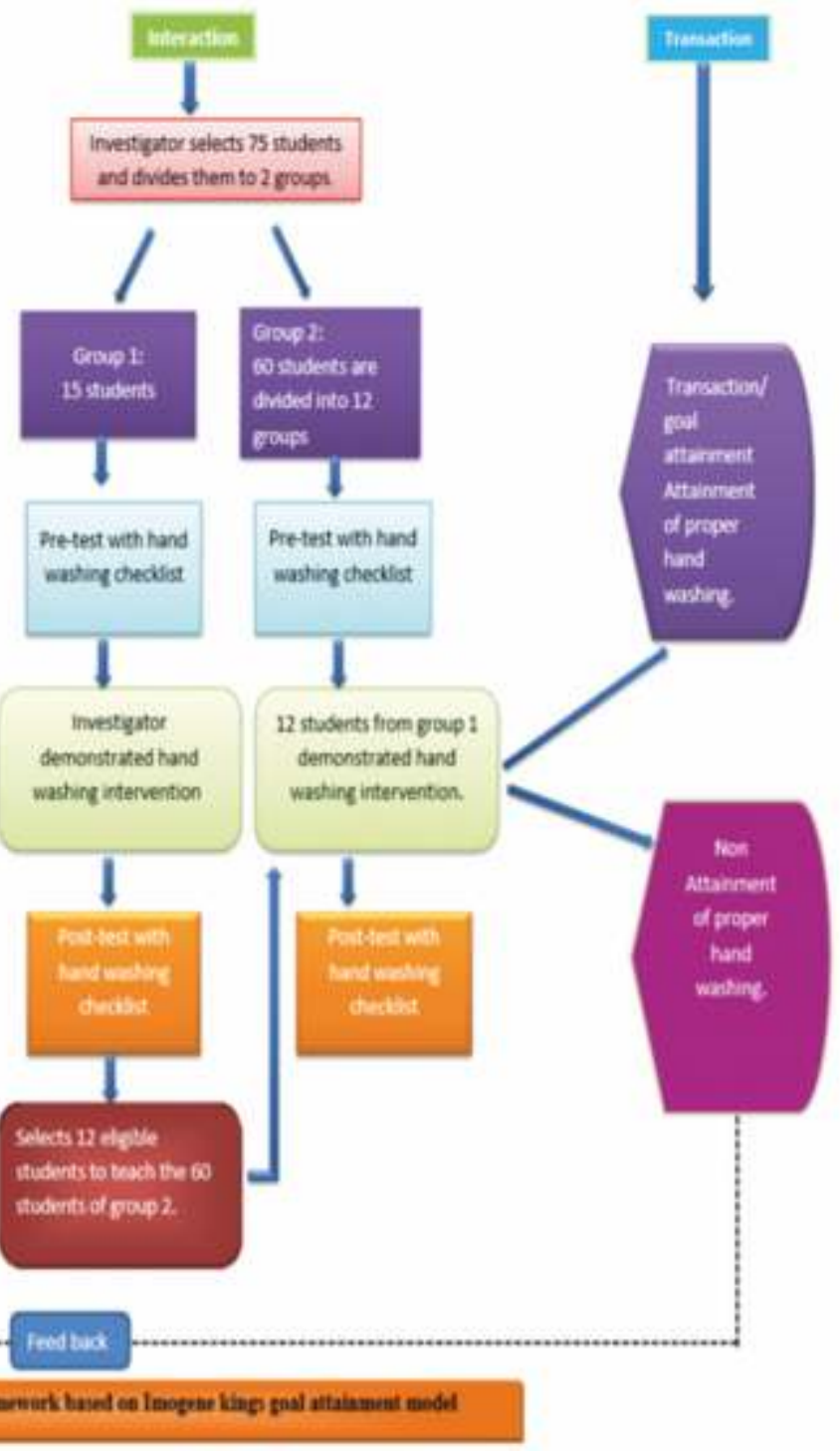

\section{M aterials and M ethods}

\section{Research approach}

An evaluative approach was used to determine the extent to which the intervention was effective in meeting its objectives.

\section{Research design}

Research design selected for the present study was one group pre-test post-test (pre experimental) design.

$01 \Rightarrow \mathrm{X} \Rightarrow \mathrm{O} 2$

$\mathrm{R}$ : randomization

01 : Assess the current hand washing practices of the school students using hand washing checklist (pretest).

$X$ : Intervention in the form of child to child approach on 
hand washing technique.

02 : Assess the hand washing practices of the school students using hand washing checklist (post-test).

Setting of the study: The present study was conducted in selected rural school (Aided higher primary school, PavoorHarekala) at $M$ angalore.

\section{Population}

The population of study comprises school children in the age group 9-10yrs who meets the inclusion criteria and studying in a rural school at $M$ angalore.

\section{Sample}

The sample size of the study comprises of 75 students within the age group 9-10yrs who meets the inclusion criteria and studying in a rural school at $\mathrm{M}$ angalore.

\section{Subject selection criteria and sampling techniques}

In this study out of 156 rural schools one rural school was selected through simple random sampling. Non-probability sampling technique and purposive sampling method was used to select the school children who are in the age group 9-10 yrs. 75 students from Aided higher primary school studying in 4th to 5th class were selected for the study. Consent and assent was taken from the parents and students respectively. The students were divided into 2 groups using purposive sampling. Group I consists of 15 students and Group II consists of 60 students. 15 students of group I were assessed for hand washing (pre-test) using checklist followed by hand washing was demonstrated by the researcher. One week later post-test was administered by using the same hand washing checklist and 12 eligible students were selected to teach the 60 students in group II. Group II students were also administered pre-test using hand washing checklist by the researcher following which they were taught hand washing intervention by 12 students from group I. Post-test was conducted after one week using hand washing checklist by the researcher.

\section{Data Collection Instruments}

The following instruments were developed by the researchersfor the present Study.
Tool 1: Demographic Performa

It consist of 7 items which include age, gender, class, education of father, education of mother, monthly income and number of siblings.

Tool 2: A Checklist was used to assess the hand washing practice.

\section{Source of checklist}

In development of the instrument review of literature played a major role. The investigators developed blue print and constructed demographic proforma and hand washing check list. It was refined by the experts and peer group which was validated by 10 experts. Expert's comments were placed in front of the departmental faculty, peers and modification was made as per the suggestion.

The final checklist consists of 13 items related to hand washing practice.

Each item was given a score of 1 if that item is demonstrated by the student then they will get 1 .

If the student performs all the 13 items he/ she get a score of 13 . There are 11 essential steps and 2 desirable steps.

\section{Score interpretation}

$\geq 11$ : good hand washing (it includes all 11 essential steps with / without the 2 desirable steps)

$<11$ : poor hand washing practice (if any one of the essential hand washing steps is missed and

Even if all desirable steps are performed it is considered to be a poor hand washing practice)

\section{Content validity of the tool:}

The prepared tool along with the blue print, objectives were given to 10 experts to ensure the content validity. The experts are from the field of Pediatrics and community health nursing. Suggestions and recommendations given by the experts were accepted and necessary corrections were incorporated.

\section{Reliability}

Reliability for check list was assessed by Cronbach's alpha reliability coefficient which was 0.765 . Hence the tool is reliable to assess the effectiveness of hand washing 


\section{Pilotstudy}

The pilot study was conducted from 19/9/15 to 10/10/15 to check the reliability, feasibility and practicability of the research design. 8 students from the age group 9-10 years were selected from Belma Aided primary high school, Deralakatte. Consent was taken from the parents and assent was taken from the students respectively. The students were divided into 2 groups. Group 1 consists of 2 students and Group 2 consists of 6 students. 2 students of group1 were given pre-test using hand washing checklist followed by hand washing intervention by the researcher. One week later post-test was administered using the same hand washing checklist and both the eligible students were selected to teach the 6 students in group 2. Group 2 students were also administered pre-test using hand washing checklist by the researcher following which they were provided hand washing intervention by 2 students from group1. Post-test was given after one week using hand washing checklist by the researcher. The findings of pilot study showed that hand washing checklist was reliable, appropriate and clear.

\section{Data Collection Process}

75 students from Aided higher primary school within the age 9-10 years and studying in 4th to 5th class were selected for the study. Consent and assent was taken from the parents and students respectively. The students were divided into 2 groups using purposive sampling. Group I consists of 15 students and Group II with 60 students. Group I was given pre-test using hand washing checklist followed by hand washing technique taught by the researcher. One week later post-test was assessed using the same hand washing checklist.12 eligible students who performed all 11 essential steps with / without the 2 desirable steps were selected to teach the 60 students in Group II. Group II students were also assessed pre-test using hand washing checklist following which they were taught hand washing technique by group I. Post-test was assessed after one week using hand washing checklist.

\section{Protection of Human Subjects}

- The study was presented in institutional and central ethics committee and ethical clearance was obtained.

- Permission for the study was obtained from the school authorities.

- Informed consent from the parents and assent from the students were obtained after explaining to them the purpose, usefulness and confidentiality of their response.

\section{Statistical Analysis}

Data was analyzed by using descriptive statistics and inferential statistics on the basis of objectives and hypothesis of the study.

- Demographic proforma containing sample characteristics was analyzed by using frequency and percentage.

- Effectiveness of child to child approach on hand washing among school children was analyzed by using frequency, percentage and independent- $t$ test.

- Association between the pre-test hand washing score with selected demographic variables was analyzed using chi-square and fisher's exact test.

\section{Results}

The plan for data analysis was:

Section 1: Description of sample characteristics

Section 2: Effectiveness of child to child approach on practice of hand washing among school children

Section 3: Association between pre-test hand washing score with selected demographic variables.

Sample characteristics: The study conducted among 75 students revealed that most of the students $44(58.7 \%)$ were in the age Group 10 years, majority $48(64 \%)$ students were males. M ost of the students $44(58.7 \%)$ were from 5 th standard. Most of the student's fathers $23(30.7 \%)$ and mother's 35(46.7\%) studied up to primary education. 
Table 1 : Effect of child to child approach on hand washing practice before and after the hand washing intervention

\begin{tabular}{|c|c|c|c|c|c|c|c|c|c|}
\hline & Hand washing steps & \multicolumn{2}{|c|}{ Groupl } & \multicolumn{2}{|c|}{$n=15$} & \multicolumn{2}{|c|}{ Group II } & \multicolumn{2}{|c|}{$n=60$} \\
\hline & & \multicolumn{2}{|c|}{ Pre test } & \multicolumn{2}{|c|}{ Post test } & \multicolumn{2}{|c|}{ Pre test } & \multicolumn{2}{|c|}{ Post test } \\
\hline & & $\mathbf{F}$ & $\%$ & $\mathbf{F}$ & $\%$ & $\mathbf{F}$ & $\%$ & $\mathbf{F}$ & $\%$ \\
\hline 1 & Uniform should not touch the sink while standing. & 3 & 20 & 12 & 80 & 17 & 22.7 & 49 & 65.3 \\
\hline 2 & Hands and wrist are free from bangles, rings and watch. & 13 & 86.7 & 14 & 93.3 & 38 & 50.7 & 51 & 68 \\
\hline 3 & Wet the hands under running water (continuous). & 15 & 100 & 15 & 100 & 45 & 60 & 58 & 77.3 \\
\hline 4 & $\begin{array}{l}\text { Apply soap, wash hands and wrists vigorously covering } \\
\text { all surfaces of hands and fingers in the following sequence: } \\
\text { [Rubbing should be repeated } 5 \text { times( } 5 \text { seconds) in each } \\
\text { step in both hands ] }\end{array}$ & 15 & 60 & 15 & 100 & 44 & 58.7 & 60 & 80 \\
\hline 5 & Palm to palm & 15 & 100 & 15 & 100 & 60 & 80 & 60 & 80 \\
\hline 6 & Dorsum(back) of hands & 11 & 73.3 & 15 & 100 & 53 & 70.7 & 60 & 80 \\
\hline 7 & Interface the fingers & 4 & 26.7 & 14 & 93.3 & 22 & 29.3 & 55 & 73.3 \\
\hline 8 & Interlock the fingers and back of fingers & 0 & 0 & 15 & 100 & 2 & 2.7 & 54 & 72 \\
\hline 9 & Base of thumbs in circular motion & 0 & 0 & 15 & 100 & 4 & 5.3 & 54 & 72 \\
\hline 10 & Fingertips on palm in circular motion & 0 & 0 & 13 & 86.7 & 0 & 0 & 52 & 69.3 \\
\hline 11 & Rub the wrists in a rotating manner & 0 & 0 & 15 & 100 & 8 & 10.7 & 55 & 73.3 \\
\hline 12 & $\begin{array}{l}\text { Rinse the hand thoroughly under running water from } \\
\text { forearm to finger tips. }\end{array}$ & 1 & 6.7 & 14 & 93.3 & 2 & 2.7 & 59 & 78.7 \\
\hline 13 & Dry the hands using a tissue/clean towel/air-dry. & 0 & 0 & 15 & 100 & 1 & 1.3 & 56 & 74.7 \\
\hline
\end{tabular}

Table 2 : Effectiveness of child to child approach on practice on hand washing by using independent 't' test

\begin{tabular}{|l|c|c|c|c|c|}
\hline Groups & Mean & S.D & 't' value & 'p' value \\
\hline \multirow{2}{*}{ Group1 $\mathrm{n}=15$} & Pre test & 4.60 & 1.121 & 22.47 & $<001$ \\
\cline { 3 - 6 } & Post test & 12.46 & .915 & & \\
\hline \multirow{2}{*}{ Group II $\mathrm{n}=60$} & Pre test & 4.91 & 1.54 & 25.32 & $<001$ \\
\cline { 3 - 5 } & Post test & 12.05 & 1.46 & & \\
\hline
\end{tabular}

Effectiveness of child to child approach: Findings of Table no 2 showed that group 2 the mean post-test hand washing score (12.05) was higher as compared with mean pre-test score (4.91) the table value and for independent 't test' is 1.99 which is less than the table value 22.5 and the $p$ value is $\varangle$ 05 . So there is a difference between the mean pre-test and post-test score. Hence child to child approach is effective for teaching hand washing at $5 \%$ level of significance.

\section{Association between pre-test hand washing score and selected demographic variables:}

Association was assessed using chi-square and fisher's exact test. The calculated $p$ value for education of father (8.282), education of mother (1.525), monthly income (2.108) and number of elder siblings (7.282) is more than fisher's exact test $p$ values 0.05 . So there is no association between pre-test score of hand washing practices and selected demographic variables.

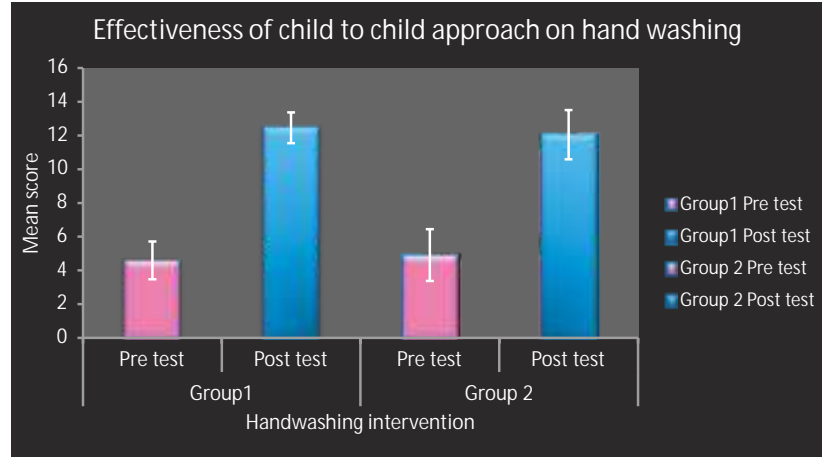

Fig 2 : Effectiveness of child to child approach on hand washing

\section{Discussion}

This study revealed that there was significant difference between mean pre-test and post-test hand washing scores. The mean pre-test hand washing scores (4.91) was less than the mean post-test hand washing score (12.05) and the ' $p$ ' value is $\varangle .05$ which was statistically significant. Hence it is inferred that child to child approach is effective in teaching hand washing. 
This study is supported by a study conducted in M angalore on effectiveness of child to child approach to health education on prevention of worm infestation among 100 students of class $V$. The mean pre and post-test knowledge scores of children of child to child approach is $4.34 \pm 4.78$.

Another supportive study conducted by M uneeswari .B to assess the effectiveness of structured teaching program using child to child approach on first aid measures among school children in Dharapuram, Tamil Nadu. 200 students of the age group 12-13 yrs were selected. The results showed that $68.5 \%$ students had improved knowledge. It concluded that child to child approach was effective to teach first aid measures to the children.

An article published in global education magazine by Celine Woznica stated that child to child program was used to improve the health of children and families in internally displaced camps in Liberia. 10 to 14 year old children were trained on basic hygienic habits like hand washing and keeping the food covered. They spread these messages by conducting dramas and health talks. The health officials noticed a drastic reduction in common health problems like fever and diarrhea. This study concluded that children are more powerful change agents than outside health workers.

A contradictory results shown in a study conducted by Le Thi than and Luu Ngoc Hoat to describe the hand washing behavior with soap and its associated factors in Vietnam. 319 students from first, fourth and seventh grade were selected and taught hand washing protocol. The results of the study showed, out of 319 students only 10 performed hand washing satisfactorily.

Though, all the above mentioned studies were on different topics it have been proved to be effective for child to child approach. Many studies have been conducted in our country on child to child approach in different areas but no study was done on hand washing with child to child approach.

The findings of the present study shows there is no significant association between pre-test hand washing score and selected demographic variables.

A supportive study was conducted by Catalina LopezQuintero to assess the hand washing practice of School Children in Bogotá, Colombia. The sample size was 2042 students from 25 schools studying in 6 th -8 th class. This study showed that age, gender, socio-economic status, mother's education, and father's education were not associated with hand-washing behavior.

From this study the researchers identified the following important barriers which hinders the practice of hand washing,

- Boys in the age of 10 years are more involved in outdoor games but are less likely to wash their hands frequently as they are unaware of the need to wash their hands frequently and must be reminded constantly of personal hygiene.

- Lack of provision for hand washing facilities at home is one of the major limitations for practicing hand washing because of low socio economic status.

- Despite of having primary education most of the parents may be unaware about the importance of hand washing and intensity of the problems caused due to failure of this habit which resulted in poor parental instructions.

\section{Conclusions}

This study reveals school children had poor hand washing practices due to lack of knowledge, poor attitude, lack of motivation, lack of hand washing facilities and poor parental instructions. This study also reveals child to child approach was an effective strategy in improving the hand washing techniques of school children. Since children are more receptive to learning and are easily moldable at a young age an elder sibling can be trained on hand washing through child to child approach may influence the hand washing practices of the younger siblings and other family members which can decrease the rate of transmission of diseases. Though schools and community has been stressing on hand washing and its importance there are many factors which will hinder this practice like scarcity of water, illiteracy, over population, poverty and lack of provision of hand washing facilities. These hindering 
factors need to be taken in to consideration so that our National motto "Swachh Bharat" will be accomplished.

\section{Nursing Implication}

- Nurses working in pediatric ward should be keen observers of hand washing practices among children and teach them the importance and technique of performing good hand washing thereby reducing the morbidity of health problems related to hand washing.

- Children's practice on health related behavior in community can greatly be influenced by child to child

\section{References}

1. National Center for Environmental Health, Division of Emergency and Environmental Health Services. vessel sanitation program. Centers for diseases control and prevention. Reviewed July 15, 2009, updated July 20, 2009. [cited on 10 oct 2014] Available from: http:// www. cdc.gov/ nceh/vsp/cruiselines/hand_hygiene_general.htm

2. Leena KC, Souza SJD. Effectiveness of child to child approach to health education on prevention of worm infestation among children of selected primary schools in Mangalore. 2014;4(1):113-5 [cited on 4 nov 2015] Availiable form: www.nitte.edu.in/journal/M arch\%202014 1113-115.pdf

3. Yalcin SS, Yalcin S, Altin S. Hand washing and adolescents. A study from seven schools in Konya, Turkey.Int J Adolesc Med Heal [Internet]. 2004;16(4):371-6 [cited on 3 jan 2015]

4. Journal G, Medicine of. Global Journal Of M edicine And Public Health $A$ study to assess the effectiveness of planned health teaching programme using child-to - child approach on knowledge of selected approach.

\section{Limitations}

- The students were in latency phase they preferred peers of same sex teaching them and many boys rejected members of opposite sex teaching them.

- Soaps were provided to individual students in the beginning of the study which many of them failed to bring for post-test. So new soaps were given for posttest.

- Generalization of the study is limited as the study involves a small group of children

first aid measures among school children in selected schools at Dharapuram in Ta. 2014;3(1) [cited on 15 jan 2015] Available from: http://www.gjmedph.org/uploads/02-Vo3No1.pdf

5. Celine Woznica. Building Resilience Through the Child-to-Child Approach. Global Education M agazine [cited on 20 dec 2015] Available from: http:// www.globaleducationmagazine.com/buildingresilience-child-to-childapproach/

6. Xuan LTT, Rheinländer T, Hoat LN, Dalsgaard A, Konradsen F. Teaching hand washing with soap for schoolchildren in a multi-ethnic population in northern rural Vietnam. Glob Health Action [Internet] 2013 Apr [cited 2015 Dec 8];6(0). Available from: www. globalhealthaction.net $>$ Home $>$ Vol 6 (2013) > Xuan

7. Lopez-Quintero C, Freeman P, NeumarkY. Hand washing among school children in Bogot??, Colombia. Am J Public Health. 2009:99(1):94-101. [cited on 18 march 2015] Available from: http://www.ncbi.nlm.nih.gov/pmc/articles/PM C2636611. 